\title{
Dominant Hand Usage in Racket Sports and Detection of the Injured Regions
}

\author{
Erkan Çetinkaya \\ Correspondence: Erkan Çetinkaya, Adnan Menderes University, Faculty of Sport Science, Aydın, Turkey.
}

Received: September 10, 2018

Accepted: October 14, $2018 \quad$ Online Published: October 22, 2018

doi:10.11114/jets.v6i12.3709

URL: https://doi.org/10.11114/jets.v6i12.3709

\begin{abstract}
The aim of this study is to examine dominant hand usage and detect the injury regions in racket sports. A total of 98 athletes, of which $37(37.8 \%)$ are female, $61(62.2 \%)$ are male, studying at 11 different universities and attending competitions with schools teams with an average age of $21.11 \pm 1.66$, height of $1.71 \pm 0.08 \mathrm{~cm}$, weight of $64.92 \pm 10.85 \mathrm{~kg}$, and BMI of $22.00 \pm 2.41\left(\mathrm{~kg} / \mathrm{m}^{2}\right)$ have participated in the study. When it comes to the distribution of the athletes by branches, the sample consists of 22 table tennis players, 24 badminton players, 25 tennis players and 27 squash players. The "Edinburgh Inventory Hand Preference Survey" was used as a data collection tool to determine the hand preferences of the athletes. In the determination of sports injuries suffered by athletes, the Cornell Musculoskeletal Discomfort Questionnaire was administered. There are significant differences between the lefty and righty athletes in terms of injuries in the left shoulder, left wrist and right lower leg regions when the injury regions in racket sports are compared by hand preferences $(\mathrm{p}<0.05)$. It is seen that the injuries that occur in right forearm, left wrist and the right upper leg regions of the athletes of racket sports differ according to branches $(\mathrm{p}<0.05)$. When the injury regions are examined according to hand preferences, it is seen that the injuries in the left shoulder, left wrist and lower right leg regions occur more in lefty athletes in comparison to righty athletes. When the relationship between the injury region regions and sports branches is examined, it can be argued that table tennis players suffer more frequent injuries in the left wrist compared to the players of other branches.
\end{abstract}

Keywords: racket sports, dominant hand, sports injuries

\section{Introduction}

There are three sport branches in our country which are expressed as racket sports and have federations. These are sports branches that could be performed and watched by everyone as performance sports and leisure time sports. The activities of these three branches, tennis, table tennis and badminton, with federations are carried out by the coordination of the Provincial Directorate of Youth and Sports with federations under the roof of the General Directorate of Youth and Sports (Kuter et al., 2006). Squash, which has yet to have a federation, has recently been added to these three branches (Zengin et al., 2006).

Tennis is a performance sport where aerobic and anaerobic loadings are applied together and that entails the bio-motor features such as strength, speed, durability, flexibility and coordination to be at an adequate level at the same time (Yanar, 2017). Also tennis is one of the categories of racquet sports that attract people of all kinds, recreational or professional and constantly growing in the world (Alp et al., 2016).Tennis is a sport which is played on a plain and hard surface with a racket by hitting a felting mantled ball over a $91 \mathrm{~cm}$ high net stretched in the middle of the court (Arslan, 2009).

Table tennis is the sports branch in which two players on both sides of a table try to pass a small ball to the other side of the table over a net stretched in the middle of the table with the help of rackets in their hands. It is also known as ping pong. Table tennis is a sports branch which allows people of all ages to participate, has an agile and amusing feature, is fun to watch as well as to play and the basic equipment such as rackets and balls can easily be supplied (Asan, 2011).

Badminton is a game played on a court divided into two with a net, with rackets and a shuttlecock which resembles a reversed parachute and is made of goose feather or plastic. It differs from other racket sports with the shuttlecock and the obligation not to touch the shuttlecock on the ground during the game (Arslan, 2009). Badminton fields are small-sized and ball can gain speed easily, badminton players need to make their movements in a short time during long rallies (Tanır et al., 2016). The flying characteristic of the shuttlecock is an important factor making badminton sports 
one of the most exciting sports in the world in terms of both playing and watching (Arslan, 2009).

Squash is a racket game played with a ball and two players against the wall. It is played against the wall with a hollow ball made of rubber. Squash is a sport that has been acknowledged by the International Olympic Committee and may take place among Olympic sports in future (Yanar, 2017).

\section{The Dominant Hand}

The hand is a vital part of the body that allows a person to interact directly with his or her environment. Since it is an edge limb of the human mind, the functional skills of the hand are numerous. Throughout their lives, people either mostly use either of their hands or both of them equally while doing their daily and sports activities. Human body is made up of a striated muscle structure that can generate the strength which is one of the most important motoric properties that play a role in athletic success and enhance the strength that it generates by developing through appropriate exercises or extending its size. In the formation of movement, muscles work together with bones and joints. Hands' forming out of striated muscle tissue due to their structural features might vary hinging upon the amount of force produced in the muscle tissue, the use of hand as a result of the technical and obligatory movements in the sports branch done, the training and the order and continuity of the training. As the hands are formed out of muscle and bone tissues, it is thought that the hands will be shaped by changing the hand structure with appropriate training exercises carried out in sports branches. In particular, hands and fingers used in sports such as basketball and handball in terms of completion of shots with respect to gripping the ball, in volleyball in terms of finger passing, blocking and hitting moves, in gymnastics in terms of adherence to the hanging tools or doing finger pushing in some tools, in rock climbing, in weightlifting in terms of gripping the bar, in the throwing branches of athletics such as javelin, discus, shot put, in sports such as badminton tennis and table tennis in terms of gripping the racket. Lefty athletes are needed in many sports. Especially those who are able to use both hands dexterously are preferred. Statistics show that the superiority of lefty athletes are remarkable in sports such as tennis, table tennis, fencing and boxing where two athletes confront with each other. In tennis world ranking, $75 \%$ of the first four athletes are lefty, while the rate drops to $25 \%$ in the first twenty and $16 \%$ in the first two hundred. In addition to being lefty, it is very important to use both hands in sports. In some cases, it becomes more important than single hand use. Particularly, the ability to use both hands dominantly or at equal dexterity in compliance with the dynamics of the sports carried out is a situation that is specifically preferred by the athletes and trainers. For these reasons, the structure and function of the hand, as well as the hand preference have a place in sports, and it becomes one of the most important factors for winning and success (Çıplak E., 2010).

Handedness is determined by the choice of the individual to dominantly use one hand in activities carried out with one hand and it is the ability to make these activities more effectively with one hand. People not only prefer one of their hands over the other, but they also usually do jobs faster and more accurately with these hands. Handedness gives the hand preference of the person for both simple and motor skills. Right-handed people are those who prefer to use their right hands and they are better when using their right hands. Left-handed handed people are those who prefer to use their right hands and they are better when using their left hands (Özsu, 2006).

\section{What is Injury?}

It is a functional disorder that occurs in a limb or sensory organ of a person as a result of an accident or any illness he/she suffers. In the literature on sports psychology, sports injury generally refers to the post-injury time loss. The National Athletic Injury / Illness Reporting System (NAIRS), which tries to find a benchmark for sports injuries, classifies sports injuries according to the time lost due to injuries as follows: it's a non-serious injury if the time lost as a result of injury is from 1 to 7 days; a moderately serious injury if it is from 8 to 21 days; a very serious injury if it's 21 days and more. Another study focusing on the types of injuries is the study on Swedish soccer players. According to this study, there are three types of injury: 1-acute injury, 2-chronic injury and 3-injury due to overloading. While they take acute injuries as trauma or accident, they address chronic injuries as injuries stemming from overloading (Aydoğan, 2014).

The main purpose is doing sports in an environment where laceration and injuries are prevented. When this is achieved, athletes can succeed in the sports they are performing thanks to their physical and mental health. It is clear that positive results will be achieved through a completely athletic, enthusiastic and willing approach. Laceration is a physical disorder that occurs during sports activities, requires medical treatment and causes the athlete to stay away from the sportive life. Unlike other pathologies, sportive injuries involve different variables, such as the severity and date of occurrence of the injury and the date on which the player begins to train with the team, or the date when he/she is ready to take part in the squad. Despite all efforts, it is seen that studies conducted in the past involve different definitions and concepts. The seriousness of injury: the seriousness of injury is determined by how long the athlete stays away from the game. According to the studies carried out by UEFA (Union of European Football Associations) the severity of the injury is divided into three categories as minor or small (a loss of 1-7 days), medium (8-28 days), and major or 
important (more than 28 days) (Mehmet S., 2010).

Sports injury involves all disorders that can be treated or may be permanent and it is a collective name given to all sorts of damages that might happen during sports activities (Yünceviz et al., 1997).

Hand is the most important organ we use in our daily life activities. Due to its anatomical structure, it is the most moving part of the upper extremity that frequently suffers injuries. Therefore, the evaluation and treatment of hand injuries is important. Although they cause lower mortality, hand, wrist and forearm injuries yield to higher levels of morbidity. They lead to serious loss of function as well as disability development. Although most of these injuries are minor injuries, they force the athlete to use leave and hence cause loss of labor. At the same time, they limit daily activities. Upper extremity traumas constitute important socio-economic problems because they require special expertise, long time of recovery, and may result in loss of labor serious injuries. Injury types range on a large spectrum ranging from soft tissue injuries and simple lacerations to complicated tissue damage, burns, fractures and amputation, and terms such as minor, mediate, serious or major are used to define the seriousness of the injury. About $50 \%$ of the injuries are minor traumas that are defined as soft tissue traumas and simple lacerations. But functional loss deteriorates and might result in injury as the seriousness of the laceration increases. While good-very good results can be achieved in only $60 \%$ of nerve injuries, $90 \%$ recovery rates can be achieved in tendon injuries at the wrist level, nevertheless this rate drops to $67 \%$ at the finger level. When broken hand fingers are viewed from the perspective of total active movement, it is still detected that patients can only achieve joint ranges of motion that are considered weak (Akca, 2012).

Today, together with growing interest in sports activities, an increase in sports injuries occur depending on activities carried out at both amateur and professional levels. The flexor and extensor tendon systems in the hand have a complex anatomy. Any part of this complex anatomy might injure during sports activities, even causing permanent disability in the athlete (Ay et al., 2012).

Sports injuries include situations of damage that come out by exceeding the limits of endurance as a result of facing a region of or the whole of the body with more than normal force. In the literature, the annual frequency of suffering sports injuries is mentioned to be at $1-2 \%$ levels. While sports injuries mostly affect the musculoskeletal system, soft tissue, bone and neural conduction elements are also injured at various extends and forms. It is detected that sports injuries often lead to muscle tendon injuries at lower extremities. Sports injuries often result from inconvenience of sports equipment and pitches, as well as athlete's lacking of the health, stamina and skills required by the sports branch that is performed. It may be possible to prevent sports injuries by improving these conditions. (Türker et al., 2011). This study is conducted to evaluate the dominant hand usage and sports injuries of university students who perform racket sports.

\section{Method}

\subsection{Participants}

A total of 98 athletes, of which $37(37.8 \%)$ are female, 61 (62.2\%) are male, studying at 11 different universities and attending competitions with schools teams with an average age of $21.11 \pm 1.66$, height of $1.71 \pm 0.08 \mathrm{~cm}$, weight of $64.92 \pm 10.85 \mathrm{~kg}$, and BMI of $22.00 \pm 2.41\left(\mathrm{~kg} / \mathrm{m}^{2}\right)$ have participated in the study. When it comes to the distribution of the athletes by branches, the sample consists of 22 table tennis players, 24 badminton players, 25 tennis player and 27 squash players.

\subsection{Data Collection Tools}

BMI $=$ Body weight $(\mathrm{kg}) /$ Length $(\mathrm{cm})^{2}$.

BMI values of all participants have been obtained by squaring their length measures and dividing it by their body weights (Sevimli, 2008).

\subsection{The Evaluation of the Surveys Applied}

The "Edinburgh Inventory (Oldfield) Hand Preference Survey" was used to determine the hand preferences of the athletes. In the survey, the athletes were asked to answer the writing, painting, throwing ball or stone, holding scissors, tooth brush, knife, fork or a shovel handle, striking matches, and opening the lid of a bottle items with one of the choices of: always left-handed, usually left-handed, with both hands, usually right-handed and always right-handed. The answers were rated between +100 and -100 according to the Geschwind score. Always left-handed choice is coded -10 , usually left-handed choice is coded -5 , with both hands choice is coded 0 , usually right-handed choice is coded +5 and always right-handed choice is coded +10 , and the scores are summed up. According to this calculation, those with $-100 /-20$ points are considered lefty; those with -20 and +20 points are considered two-handed; and those with $+20 /+100$ points are considered righty (Çağlar B., 2016). 
The Muscle-Skeletal System Questionnaire was administered to identify the injuries that the athletes suffered. The data obtained from the survey was evaluated over frequency and percentage tables. Commonly used surveys on musculoskeletal disorders in the literature are The Nordic Musculoskeletal Questionnaire, the Dutch Musculoskeletal Questionnaire and the Cornell Musculoskeletal Discomfort Questionnaire. Developed by Hedge et al., the Cornell Musculoskeletal Disorders Questionnaire is mainly based on the The Nordic Musculoskeletal Questionnaire. The Cornell Musculoskeletal Disorders Questionnaire is used to determine musculoskeletal disorders in the fields such as computer jobs, health sector and mounting line in which recurrent movements are done. The questionnaire was translated into Turkish and its validity and reliability was tested by Erdinç et al. Unlike the evaluation methods of the Nordic and Dutch Musculoskeletal Surveys, the Cornell Musculoskeletal System Disorders Questionnaire is based on the scoring system. In the evaluation of this questionnaire, the total discomfort score of different regions of the body is calculated by multiplying the scores of frequency, severity, impacts of the discomfort on the work, and the regions with the highest percentage score compared to the total score of all body regions evaluated in the questionnaire are used to determine the body regions with the most serious problems. When the evaluation system of the Cornell Musculoskeletal Disorders Questionnaire is compared with the Dutch and Nordic questionnaires, it can be argued that the former has a more comprehensive evaluation system since it calculates score points rather than merely examining the frequencies (Gönen et al., 2018).

\subsection{Data Analysis}

The data obtained from the survey application for the purpose of determining injuries suffered by the athletes participating in the study were collected by the author, and the deficiently or incorrectly filled forms were singled out of the study. Then, the forms that were considered to have valid and acceptable quality were transferred into SPSS package program and analyzed through the SPSS 22.0 package program at a 95\% confidence interval and 0.05 significance level. The Kolmogorov-Smirnov Test was used to determine whether the data showed normal distribution. Seeing that the distribution of the data was normal, Independent Sample T test was used to test whether there is difference between the mean scores of two independent sample groups; and One Way Anova test was used to determine whether there is difference among three or more independent means. As well as frequency distributions based on branches and genders, the minimum, maximum, mean and standard deviation values of age, height, body weight and Body Mass Index (BMI) values of the athletes participating in the study were calculated.

\section{Results}

Table 1. Distribution of Athletes According to Their Branches and Genders

\begin{tabular}{|c|c|c|c|c|c|}
\hline \multirow{3}{*}{ Branches } & \multicolumn{4}{|c|}{ Gender } & \multirow{3}{*}{ Total } \\
\hline & \multicolumn{2}{|c|}{ Female } & \multicolumn{2}{|c|}{ Male } & \\
\hline & $\mathbf{N}$ & $\%$ & $\mathbf{N}$ & $\%$ & \\
\hline Table Tennis & 10 & 45.5 & 12 & 54.5 & 22 \\
\hline Badminton & 9 & 37.5 & 15 & 62.5 & 24 \\
\hline Tennis & 7 & 28.0 & 18 & 72.0 & 25 \\
\hline Squash & 11 & 40.7 & 16 & 59.3 & 27 \\
\hline Total & 37 & 100 & 61 & 100 & 98 \\
\hline
\end{tabular}

Table 1. presents the distribution of athletes according to their branches and genders. Number of observations for all parameters is 98 .

Table 2. Descriptive Statistics of the Athletes

\begin{tabular}{lcccc}
\hline Variables & Minimum & Maximum & X & Sd \pm \\
\hline Age (year) & 18 & 26 & 21.11 & 1.66 \\
Height $(\mathrm{cm})$. & 1.53 & 1.98 & 1.71 & 0.08 \\
Weight $(\mathrm{kg})$. & 48 & 95 & 64.92 & 10.85 \\
Body Mass Index $\left(\mathrm{kg} / \mathrm{cm}^{2}\right)$ & 15.32 & 27.04 & 22.00 & 2.41 \\
\hline
\end{tabular}

Table 2. presents descriptive statistics on age, height, body weight, and Body Mass Index (BMI) values of the athletes participating in the study.

Table 3. Comparison of Athletes' Injury Regions by Gender

\begin{tabular}{lccccccc}
\hline \multirow{2}{*}{ Injured extremity } & Gender & $\mathbf{N}$ & $\mathbf{X}$ & $\mathbf{S d} \pm$ & $\mathbf{S}_{\text {error }}$ & \multicolumn{2}{c}{$\mathbf{T}$ test } \\
\hline \multirow{2}{*}{ Total disability score } & Female & 37 & 24.95 & 26.58 & 4.37 & 0.273 & 0.785 \\
& Male & 61 & 23.26 & 31.23 & 3.99 & & \\
\hline
\end{tabular}


Table 3. shows that there is no significant difference between male and female athletes in terms of injury regions ( $>0.05$ ). Accordingly, it can be claimed that gender does not have a significant impact on the injuries suffered by the athletes of racket sports.

Table 4. Comparison of Athletes' Injury Regions by Hand Preferences

\begin{tabular}{|c|c|c|c|c|c|c|c|}
\hline \multirow{2}{*}{ Injured extremity } & \multirow{2}{*}{$\begin{array}{c}\text { Hand } \\
\text { preferences }\end{array}$} & \multirow{2}{*}{$\mathbf{N}$} & \multirow{2}{*}{$\mathbf{X}$} & \multirow{2}{*}{ Sd \pm} & \multirow{2}{*}{$\mathbf{S}_{\text {error }}$} & \multicolumn{2}{|c|}{ T test } \\
\hline & & & & & & $\mathbf{t}$ & $\mathbf{p}$ \\
\hline \multirow{2}{*}{ Neck region } & Left hand & 18 & 2.00 & 3.37 & 0.79 & 0.120 & 0.905 \\
\hline & Right hand & 80 & 1.90 & 3.15 & 0.35 & & \\
\hline \multirow{2}{*}{ Right shoulder region } & Left hand & 18 & 0.89 & 2.92 & 0.69 & -1.030 & 0.306 \\
\hline & Right hand & 80 & 2.55 & 6.67 & 0.74 & & \\
\hline \multirow{2}{*}{ Left shoulder region } & Left hand & 18 & 3.11 & 4.91 & 1.15 & 1.997 & 0.049 \\
\hline & Right hand & 80 & 1.15 & 3.46 & 0.38 & & \\
\hline \multirow[b]{2}{*}{ Back region } & Left hand & 18 & 1.89 & 4.36 & 1.02 & -0.527 & 0.600 \\
\hline & Right hand & 80 & 2.85 & 7.44 & 0.83 & & \\
\hline \multirow{2}{*}{ Right upper arm region } & Left hand & 18 & 4.61 & 12.38 & 2.91 & 0.952 & 0.343 \\
\hline & Right hand & 80 & 2.66 & 6.46 & 0.72 & & \\
\hline \multirow{2}{*}{ Left upper arm region } & Left hand & 18 & 1.44 & 3.34 & 0.78 & 1.949 & 0.054 \\
\hline & Right hand & 80 & 0.43 & 1.57 & 0.17 & & \\
\hline \multirow{2}{*}{ Waist region } & Left hand & 18 & 4.06 & 8.85 & 2.08 & 0.002 & 0.998 \\
\hline & Right hand & 80 & 4.05 & 9.41 & 1.05 & & \\
\hline \multirow{2}{*}{ Right forearm region } & Left hand & 18 & 3.72 & 11.32 & 2.66 & 0.766 & 0.446 \\
\hline & Right hand & 80 & 2.20 & 6.55 & 0.73 & & \\
\hline \multirow{2}{*}{ Left forearm region } & Left hand & 18 & 2.44 & 5.38 & 1.26 & 1.342 & 0.183 \\
\hline & Right hand & 80 & 0.96 & 3.94 & 0.44 & & \\
\hline \multirow{2}{*}{ Right wrist region } & Left hand & 18 & 1.28 & 4.72 & 1.11 & -0.833 & 0.407 \\
\hline & Right hand & 80 & 2.83 & 7.54 & 0.84 & & \\
\hline \multirow{2}{*}{ Left wrist region } & Left hand & 18 & 4.67 & 10.35 & 2.44 & 2.485 & 0.015 \\
\hline & Right hand & 80 & 0.93 & 4.17 & 0.46 & & \\
\hline \multirow{2}{*}{ Hip region } & Left hand & 18 & 0.78 & 2.84 & 0.66 & -0.503 & 0.616 \\
\hline & Right hand & 80 & 1.36 & 4.72 & 0.52 & & \\
\hline \multirow{2}{*}{ Right upper leg region } & Left hand & 18 & 1.78 & 4.64 & 1.09 & -0.264 & 0.792 \\
\hline & Right hand & 80 & 2.15 & 5.55 & 0.62 & & \\
\hline \multirow{2}{*}{ Left upper leg region } & Left hand & 18 & 1.89 & 6.37 & 1.50 & 1.323 & 0.189 \\
\hline & Right hand & 80 & 0.73 & 2.25 & 0.25 & & \\
\hline \multirow{2}{*}{ Right knee region } & Left hand & 18 & 2.00 & 5.17 & 1.22 & -0.036 & 0.971 \\
\hline & Right hand & 80 & 2.06 & 6.88 & 0.77 & & \\
\hline \multirow{2}{*}{ Left knee region } & Left hand & 18 & 0.22 & 0.94 & 0.22 & -0.295 & 0.768 \\
\hline & Right hand & 80 & 0.33 & 1.40 & 0.15 & & \\
\hline \multirow{2}{*}{ Lower right leg region } & Left hand & 18 & 5.22 & 14.50 & 3.41 & 2.564 & 0.012 \\
\hline & Right hand & 80 & 0.85 & 2.58 & 0.28 & & \\
\hline \multirow{2}{*}{ Lower left leg region } & Left hand & 18 & 1.17 & 3.29 & 0.77 & 0.937 & 0.351 \\
\hline & Right hand & 80 & 0.54 & 2.39 & 0.26 & & \\
\hline & Left hand & 18 & 30.11 & 25.01 & 5.89 & 0.991 & 0.324 \\
\hline Total disability score & Right hand & 80 & 22.50 & 30.30 & 3.38 & & \\
\hline
\end{tabular}

In Table 4 . when athletes' injury regions are compared by their hand preferences, significant differences $(\mathrm{p}<0.05)$ between righty and lefty athletes are seen in terms of certain body regions (left shoulder, left wrist and right lower leg). According to this finding, lefty athletes suffer more injuries in their left shoulder, left wrist and lower right leg regions than righty athletes. On the other hand, no significant differences ( $p>0.05)$ were found between righty and lefty athletes in terms of injuries that occur in the neck, right shoulder, back, upper right arm, left upper arm, waist, right forearm, left forearm, right wrist, hips, right upper leg, left upper leg, right knee, left knee and left lower leg regions. 
Table 5. Comparison of Athletes' Injury Regions by Branches

\begin{tabular}{|c|c|c|c|c|c|c|c|c|}
\hline Injured extremity & & Branches & $\mathbf{N}$ & $\mathbf{X}$ & Sd \pm & $\mathbf{F}$ & $\mathbf{p}$ & Difference \\
\hline \multirow{4}{*}{ Neck region } & 1 & Table tennis & 22 & 1.09 & 2.48 & 0.728 & 0.538 & \\
\hline & 2 & Badminton & 24 & 1.92 & 2.58 & & & \\
\hline & 3 & Tennis & 25 & 2.40 & 4.35 & & & \\
\hline & 4 & Squash & 27 & 2.15 & 2.90 & & & \\
\hline \multirow{4}{*}{ Right shoulder region } & 1 & Table tennis & 22 & 2.36 & 6.63 & 0.101 & 0.959 & \\
\hline & 2 & Badminton & 24 & 2.63 & 7.52 & & & \\
\hline & 3 & Tennis & 25 & 1.68 & 5.02 & & & \\
\hline & 4 & Squash & 27 & 2.33 & 5.75 & & & \\
\hline \multirow{4}{*}{ Left shoulder region } & 1 & Table tennis & 22 & 2.09 & 4.55 & 0.266 & 0.850 & \\
\hline & 2 & Badminton & 24 & 1.08 & 3.06 & & & \\
\hline & 3 & Tennis & 25 & 1.44 & 4.91 & & & \\
\hline & 4 & Squash & 27 & 1.48 & 2.57 & & & \\
\hline \multirow{4}{*}{ Back region } & 1 & Table tennis & 22 & 1.73 & 5.90 & 1.091 & 0.357 & \\
\hline & 2 & Badminton & 24 & 3.33 & 5.07 & & & \\
\hline & 3 & Tennis & 25 & 4.40 & 9.92 & & & \\
\hline & 4 & Squash & 27 & 1.26 & 5.76 & & & \\
\hline \multirow{4}{*}{ Right upper arm region } & 1 & Table tennis & 22 & 4.05 & 9.82 & 0.977 & 0.407 & \\
\hline & 2 & Badminton & 24 & 1.25 & 2.62 & & & \\
\hline & 3 & Tennis & 25 & 2.16 & 3.91 & & & \\
\hline & 4 & Squash & 27 & 4.56 & 11.1 & & & \\
\hline \multirow{4}{*}{ Left upper arm region } & 1 & Table tennis & 22 & 1.27 & 3.05 & 1.061 & 0.370 & \\
\hline & 2 & Badminton & 24 & 0.33 & 0.96 & & & \\
\hline & 3 & Tennis & 25 & 0.36 & 1.03 & & & \\
\hline & 4 & Squash & 27 & 0.56 & 2.35 & & & \\
\hline & 1 & Table tennis & 22 & 3.55 & 9.25 & 0.786 & 0.505 & \\
\hline Waist region & 2 & Badminton & 24 & 3.71 & 4.73 & & & \\
\hline & 3 & Tennis & 25 & 6.40 & 13.4 & & & \\
\hline & 4 & Squash & 27 & 2.59 & 7.48 & & & \\
\hline & 1 & Table tennis & 22 & 5.59 & 11.3 & 2.785 & 0.045 & $1-2$ \\
\hline Right forearm region & 2 & Badminton & 24 & 0.29 & 0.69 & & & $1-3$ \\
\hline & 3 & Tennis & 25 & 0.56 & 1.78 & & & $2-4$ \\
\hline & 4 & Squash & 27 & 3.67 & 9.56 & & & $3-4$ \\
\hline & 1 & Table tennis & 22 & 2.64 & 5.99 & 1.510 & 0.217 & \\
\hline & 2 & Badminton & 24 & 0.50 & 1.35 & & & \\
\hline Left forearm region & 3 & Tennis & 25 & 0.32 & 1.60 & & & \\
\hline & 4 & Squash & 27 & 1.59 & 5.59 & & & \\
\hline & 1 & Table tennis & 22 & 3.73 & 8.00 & 0.358 & 0.783 & \\
\hline Right wrist region & 2 & Badminton & 24 & 1.54 & 3.43 & & & \\
\hline & 3 & Tennis & 25 & 2.60 & 9.27 & & & \\
\hline & 4 & Squash & 27 & 2.41 & 6.70 & & & \\
\hline & 1 & Table tennis & 22 & 5.05 & 11.0 & 3.538 & 0.018 & $1-2$ \\
\hline & 2 & Badminton & 24 & 0.83 & 3.67 & & & $1-3$ \\
\hline Left wrist region & 3 & Tennis & 25 & 0.08 & 0.40 & & & $1-4$ \\
\hline & 4 & Squash & 27 & 0.93 & 2.75 & & & \\
\hline & 1 & Table tennis & 22 & 1.68 & 5.91 & 1.964 & 0.125 & \\
\hline Hip region & 2 & Badminton & 24 & 2.88 & 6.53 & & & \\
\hline & 3 & Tennis & 25 & 0.20 & 0.70 & & & \\
\hline & 4 & Squash & 27 & 0.44 & 1.60 & & & \\
\hline & 1 & Table tennis & 22 & 0.55 & 2.55 & 2.714 & 0.049 & $1-2$ \\
\hline Right upper leg region & 2 & Badminton & 24 & 3.50 & 5.31 & & & $1-3$ \\
\hline & 3 & Tennis & 25 & 3.68 & 8.42 & & & $2-4$ \\
\hline & 4 & Squash & 27 & 0.59 & 1.90 & & & $3-4$ \\
\hline & 1 & Table tennis & 22 & 0.14 & 0.64 & 0.814 & 0.489 & \\
\hline Left upper leg region & 2 & Badminton & 24 & 1.17 & 2.69 & & & \\
\hline & 3 & Tenis & 25 & 0.72 & 1.90 & & & \\
\hline & 4 & Squash & 27 & 1.59 & 5.61 & & & \\
\hline & 1 & Table tennis & 22 & 3.45 & 8.23 & 0.681 & 0.566 & \\
\hline & 2 & Badminton & 24 & 1.58 & 7.34 & & & \\
\hline Right knee region & 3 & Tennis & 25 & 0.84 & 1.90 & & & \\
\hline & 4 & Squash & 27 & 2.44 & 7.23 & & & \\
\hline & 1 & Table tennis & 22 & 0.18 & 0.85 & 0.450 & 0.718 & \\
\hline Left knee region & 2 & Badminton & 24 & 0.17 & 0.81 & & & \\
\hline & 3 & Tennis & 25 & 0.56 & 1.78 & & & \\
\hline & 4 & Squash & 27 & 0.30 & 1.54 & & & \\
\hline & 1 & Table tennis & 22 & 4.45 & 13.2 & 1.776 & 0.157 & \\
\hline Lower right leg region & 2 & Badminton & 24 & 1.13 & 2.59 & & & \\
\hline & 3 & Tennis & 25 & 1.16 & 3.26 & & & \\
\hline & 4 & Squash & 27 & 0.30 & 1.54 & & & \\
\hline & 1 & Table tennis & 22 & 0.05 & 0.21 & 1.485 & 0.224 & \\
\hline & 2 & Badminton & 24 & 1.50 & 4.34 & & & \\
\hline Lower left leg region & 3 & Tennis & 25 & 0.76 & 2.20 & & & \\
\hline & 4 & Squash & 27 & 0.30 & 1.54 & & & \\
\hline & 1 & Table tennis & 22 & 33.1 & 27.4 & 1.138 & 0.338 & \\
\hline Total disability score & 2 & Badminton & 24 & 17.4 & 19.5 & & & \\
\hline & 3 & Tennis & 25 & 22.4 & 44.4 & & & \\
\hline & 4 & Squash & 27 & 23.5 & 18.7 & & & \\
\hline
\end{tabular}


Table 5. shows that injuries that the athletes of racket sports suffer significantly differ $(\mathrm{p}<0.05)$ in the right front arm, left wrist and right upper leg regions when compared by their branches. According to this finding, it can be argued that the injuries that occur in the right forearm are more frequently seen among table tennis and squash players. In addition, table tennis players might suffer wrist injuries more frequently. Tennis players are those who suffer the most frequent injures in the upper right leg regions. Tennis players are followed by badminton players. However, no significant difference ( $p>0.05$ ) was found among badminton, table tennis, tennis and squash athletes in terms of injuries seen in neck, right shoulder, left shoulder, back, upper right arm, left upper arm, waist, left forearm, right wrist, hip, left upper leg, right knee, left knee, right lower leg and left lower leg regions.

\section{Discussion}

This study has been conducted to determine the dominant hand use preferences and the injury regions of the athletes of racket sports. A total of 98 athletes, of which 37 (37.8\%) are female, 61 (62.2\%) are male, studying at 11 different universities and attending competitions with schools teams with an average age of $21.11 \pm 1.66$, height of $1.71 \pm 0.08 \mathrm{~cm}$, weight of $64.92 \pm 10.85 \mathrm{~kg}$, and BMI of $22.00 \pm 2.41\left(\mathrm{~kg} / \mathrm{m}^{2}\right)$ have participated in the study. When it comes to the distribution of the athletes by branches, the sample consists of 22 table tennis players, 24 badminton players, 25 tennis player and 27 squash players. The discussion of the findings obtained according to these objectives are given below. The discussion and evaluation will be made on the basis of scientific foundations related to the variables.

Özsu S. (2006) found that the hand preference distribution of 185 male and female basketball athletes was $8.65 \%$ left hand and $91.35 \%$ right hand. When the hand preference distribution is examined by gender, 3.30\% of 121 males had a strong left hand, $3.30 \%$ were partially left-handed, $30.58 \%$ were partially right-handed, $62.81 \%$ had a strong right hand while $4.69 \%$ of 64 females had a strong left hand, $7.81 \%$ were partially left-handed, $25 \%$ were partially right-handed and $62.50 \%$ had a strong right hand (Özsu S., 2006).

In a study by Mikheev et al. (2002) it is reported that $94 \%$ of high-level judo athletes prefer right-hand and $6 \%$ prefer left-hand (Mikheev et al., 2002).

Sallis et al. (2001) found that $856(45.7 \%)$ of the 1874 injuries observed in female and male athletes in different branches such as basketball, cross-country race, football, swimming, tennis, jumping-throwing were suffered by females and $1018(54.3 \%)$ by males. Given the totals, it was found that males suffer more injuries in sports branches, however, there was no statistically significant difference according to gender (Sallis et al., 2001).

In the study entitled Injuries Suffered by Students of Physical Training and Sports College, Can (2003) reported that males suffer more injuries in basketball, volleyball and athletics branches yet, that this difference is not statistically significant (Can et al., 2003).

In the study entitled An Examination of Frequencies, Risk Factors and Formation Types of Injuries of Students at Elementary Education Institutions (14-17 years old), Yllmaz (2011) found that sports injury regions are mostly branch-specific and the regions that suffer the most injury is the ankle $(22.2 \%)$, and that when the injury regions of the participants are examined, ankle turned out to be the region suffering the most injuries (22.2\%). The rate of athletes who suffered back injury was the lowest $(0.3 \%)$. Females mostly suffer right ankle $(17.3 \%)$, right wrist $(11.5 \%)$, the right hand finger (10.6\%) injuries whereas right ankle (14.8\%) groin $(11.1 \%)$ and right knee $(10.1 \%)$ injuries are more frequently seen among males. No significant difference was found when injury regions were examined according to gender (Yilmaz E., 2011).

In the study, the sample of which consisted of 83 high level Slovenian athletes, examining injury frequency, type and severance of injuries among table tennis, tennis, and badminton (racket sports) athletes, Kondric. M et al. (2011) reported that table tennis is among lower risk sports and that the injury regions are shoulder belt (17.27\%), spine $(16.55 \%)$ ankle (15.83\%), foot (10.07\%) and wrist (12.23\%) (Kondric et al., 2011).

In the study on table tennis players, Ebadi A. (2014) found that the most frequently injured regions were hand-wrist and shoulder regions followed by the elbow and arm. Also explained least common injuries were in knee and foot regions (Ebadi A., 2014).

In their study on racket sports, Jayanthi. N and Esser, S (2013) reported that, young and elite tennis players mostly suffer acute and lower extremity injuries as well as severe stress injuries due to overuse. In addition, they report that acute and traumatic injuries are seen less frequently, although having less data on squash and badminton which are other racket sports (Jayanthi and Esser 2013).

Durmaz (2009) reported in his study entitled "Hand and Wrist Problems in Athletes" (extensor carpi ulnaris tendinitis) that wrist injuries occur mostly due to the backhand move in racket sports, and that these injuries occur even more frequently in the non-dominant hand of tennis players and in sports in which the backhand move is used in both hands (Durmaz, 2009). 
In the study on Squash, one of the racket sports, Atik A. et al. (2012) stated that lower extremity and eye are the regions that are most commonly injured (Atik et al., 2012).

In their 2011 study, Türker et al. (2011) state that other studies on sports injuries revealed that the body region that is affected the most was the lower extremities and that the ankle and knee regions are the most commonly injured ones. This value was found to be $93 \%$ in Emery et al. (2009) study on high school students in Canada and to be $94 \%$ in their 2006 study on adolescents (Türker et al., 2011).

According to Gaw, C.E et al. (2014), lower extremities were the body regions where tennis-related injuries treated in the US Emergency Services between 1990 and 2011 were encountered most commonly (42.2\%). This was followed by the upper extremity $(26.7 \%)$ and it was found in the study that ankle accounted for $(47.2 \%)$ of the lower extremity injuries while wrist accounted for (34.8\%) of the upper extremity injuries (Gaw, C.E et al., 2014).

Kauzlaric (2007) reports in his study on 125 school children, of which 85 are males (with 11.7 age average) and 45 are females (with 11.1 age average), that foot pain related to sports is reported mostly by the athletes of basketball (32\%), football $(26 \%)$, athletics $(15 \%)$, handball $(9 \%)$, dance $(8 \%)$, tennis $(5 \%)$, and martial arts $(3 \%)$ and in a very few number of volleyball players (2\%).

\section{Conclusion}

In line with the findings of the study it was concluded that gender has no significant effect on injuries suffered by the athletes of racket sports. When the injury regions are examined according to the hand preference, it is seen that the injuries in the left shoulder, left wrist and lower right leg regions, occur more in lefty athletes than righty athletes. When the relationship between the injury regions and sports branches is examined, it can be argued that table tennis players suffer more frequent injuries in the left wrist compared to the players of other branches, and table tennis and squash players suffer more frequent injuries in the right forearm in comparison to the players of other branches. In addition, branches in which injuries are most commonly seen in right upper region are detected to be tennis and badminton respectively.

It is seen that sports injuries have been more intensely seen in extremity regions which are mostly used in sports branches. In particular, it will have a decisive impact on the determination of all kinds of health problems suffered by the elite level athletes that may arise during the training or competition and the handling and evaluation of the related measures.

\section{References}

Akca, H. (2012). Cost analysis of patients with traumatic hand injury, Residency Thesis, Department of Physical Medicine and Rehabilitation, Pamukkale University School of Medicine, Denizli.

Alp, M., Suna, G., \& Baydemir, B. (2016). Effects of the Preparation Period Trainings on Biomotoric Features of 10-12 Age Male Tennis Players. General Information about Sstb Journal, 89.

Arslan, Y. (2009). A comparison of some anthropometric characteristics and their proportional relations of elite badminton and tennis players. Master Thesis, Gazi University, Institute of Health Science, Department of Physical Education and Sport, Ankara.

Asan, R. (2011). The effect of eight-week table tennis exercise related to the attention among 9-13 aged children. Master Thesis, Selçuk University, Institute of Health Science, Department of Physical Education and Sport, Konya.

Atik, A., Krilis, M., \& Parker, G. (2012). Squash (Ed): Craniofacial and vertebral injury from collision on squash court. Journal of emergencies, trauma, and shock, 5(4), 360-362. https://doi.org/10.4103/0974-2700.102415

Ay, Ş., Güner, D., Bektaş, U., \& Demirtaş, M. (2012). Tendon injuries of the hand in athletes. Journal of TOTBID Dergisi, 11(3), 201-213. https://doi.org/10.5606/totbid.dergisi.2012.27

Aydoğan, Z. (2014). Psychological Changes in Athletes during Injury and After Treatment. Master Thesis, Ankara University, Institute of Health Science, Department of Physical Education and Sport, Ankara.

Çağlar, B. M. (2016). The Research on the Relation among the Secondary School Students' Hand Preferences, Eye Dominance and Hearing Time with the Theory of Multiple Intelligence. Master Thesis, Atatürk University, Institute of Health Science, Department of Physical Education and Sport, Erzurum.

Çıplak, E. M. (2010). Sporcularin El Performanslarinin Finger Tapping (Parmak Vuruş) Yöntemi İle Değerlendirilmesi, Doctoral Thesis, Gazi University, Institute of Health Science, Department of Physical Education and Sport, Ankara.

Durmaz, H. (2009). Sporcularda el ve el bileği sorunları. Klinik Gelişim, 22, 119-124. 
Ebadi, A. L. (2014). Analysing Of The Types Of Injuries Observed In Table Tennis Players According To The Some Variables. Master Thesis, Gazi University, Institute of Health Science, Department of Physical Education and Sport, Ankara.

Gaw, C. E., Chounthirath, T., \& Smith, G. A. (2014). Tennis-related injuries treated in United States emergency departments, 1990 to 2011. Clinical Journal of Sport Medicine, 24(3), 226-232.

Gönen, D., Karaoglan, A. D., Ocaktan, M. A. B., Oral, A., Atıcı, H., \& Kaya, B. (2018). A new risk assessment approach for the analysis of musculoskeletal disorders. Journal of the Faculty of Engineering and Architecture of Gazi University, 33(2), 423-438.

Jayanthi, N., \& Esser, S. (2013). Racket sports. Current Sports Medicine Reports, 12(5), 329-336. https://doi.org/10.1249/JSR.0b013e3182a4bad0

Kauzlaric, N. (2007). The Use of Foot Orthoses in School Children With Foot Problems Due to Sports and Other Physical Activities. Acta Med Croatica, 61(1), 15-17.

Kondrič, M., Matković, B., Furjan-Mandić, G., Hadžić, V., \& Dervišević, E. (2011). Injuries in Racket Sports among Slovenian Players. Collegium antropologicum, 35(2), 413-417.

Kuter, F. Ö., Koparan, Ş., \& Mehmet, E. F. E. (2006). Bursa İli Raket Sporları Profili. Journal of Uludağ University Faculty of Education, 19(1).

Mehmet, S. (2010). Definitions in Sports Injuries. Turkiye Klinikleri J Orthop \& Traumatol-Special Topics, 3(1).

Mikheev, M., Mohr, C., Afanasiev, S., Landis, T., \& Thut, G. (2002). Motor control and cerebral hemispheric specialization in highly qualified judo wrestlers. Neuropsychologia, 40, 1209-1219. https://doi.org/10.1016/S0028-3932(01)00227-5

Özsu, S. M. (2006). The Investigation of Relationship Between Dominant Hand and Foot With Hand and Foot Preferences Which Are Being Used in the Basic Basketball Skills. Doctoral Thesis, Marmara University, Institute of Health Science, Department of Physical Education and Sport, İstanbul.

Sallis, R. E., Jones, K., Sunshine, S., Smith, S., \& Simon, L. (2001). Comparing Sports Injuries In Men And Women. International Journal of Sport Medicine, 22(6), 420-423. https://doi.org/10.1055/s-2001-16246

Sevimli, D. (2008). Investigation of the Relationship between Body Mass Index and Physical Activity in Adults. TAF Prev Med Bull, 7(6), 523-528.

Süleyman, C. A. N., Gürsoy, R., Ezirmik, N., \& Şenol, D. A. N. E. (2003). Sport injuries in students of departments of physical education and sport. Gazi Journal of Physical Education and Sport Science, 8(3), 59-64.

Tanır, H., Güçlüöver, A., \& Duvan, A. (2016). The effects of anthropometric structure on some motoric features among hearing imparred national team sub-junırs badminton players. International Journal of Academic Research, 8(1), $5-10$.

Türker, T., Koçak, N., İstanbulluoğlu, H., Yıldırım, A. O., Kır, T., Açıkel, C., \& Kılıç, S. (2011). Evaluation of sport habits and sport injuries in medical students. Gülhane Journal of Medicine, 53, 94-98.

Yanar, N. (2017). Analysis Of The Emotional Intelligence of Tennis, Squash and Badminton Players. Master Thesis, Uludağ University, Institute of Health Science, Department of Physical Education and Sport, Bursa.

Yılmaz, Ş. E. (2011). Orta öğretim kurumlarındaki öğrencilerin (14-17 yaş) spor yaralanma slkliklarl, risk faktörleri ve oluşum şekillerinin incelenmesi: (Burdur İli örneği) (Doctoral dissertation, Süleyman Demirel University School of Medicine).

Yünceviz, R., Karsan, O., Dane, S.., \& Can, S. (1997). Injury variation around body in free and Greco-Roman wrestlers. Gazi University Journal of Physical Education and Sport Science, 2(1), 13-17, Ankara.

Zengin, E., Sertbaş, K., \& Kolayiş, H. (2006). Studying The Free Time Profiles And The Interest Shown in Racket Sports of The Students Of Physical Training And Sports College of The University of Kocaeli. Spor Yönetimi ve Bilgi Teknolojileri, 1(1).

\section{Copyrights}

Copyright for this article is retained by the author(s), with first publication rights granted to the journal.

This is an open-access article distributed under the terms and conditions of the Creative Commons Attribution license which permits unrestricted use, distribution, and reproduction in any medium, provided the original work is properly cited. 